\title{
GEOCOR: Descobrindo as Cores das Bandeiras dos Estados do Brasil
}

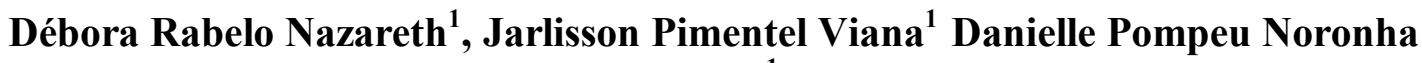 \\ Pontes $^{1}$ \\ ${ }^{1}$ Universidade do Estado do Amazonas (UEA) - Escola Superior de Tecnologia (EST) \\ Av. Darcy Vargas, 1200, Parque Dez - Manaus - AM - Brazil \\ debora.inforc@gmail.com, jarlisson.viana@hotmail.com, \\ dnoronha@uea.edu.br
}

\begin{abstract}
The technologies applied in education allow the teaching-learning process are innovative, making classes more dynamic and less tiring. The purpose of this work is to develop an educational software applied to the discipline of Geography of Brazil, causing the student to learn what the Brazilian states, their flags and their colors through a game named "GeoCor", where you should select the color match flag.
\end{abstract}

Resumo. As tecnologias aplicadas na educação permitem que o processo ensino-aprendizagem sejam inovadores, tornando as aulas mais dinâmicas e menos cansativas. A proposta deste trabalho é desenvolver um software educativo aplicado à disciplina de Geografia do Brasil, fazendo com que o aluno aprenda quais os estados brasileiros, suas bandeiras e as respectivas cores através de um jogo nominado "GeoCor", onde deverá escolher a cor corresponde à bandeira.

\section{Cenário de Uso}

A descoberta de novos métodos para o desenvolvimento do aprendizado é um pressuposto para a evolução da forma de ensinar. Não é apenas o que é ensinado em sala de aula e sim como o é feito. É trazer a atenção do aluno para aquilo que lhe deixa curioso e atiça sua mente para aprender.

Pelo método construtivista, o aluno é o principal responsável pela sua aprendizagem. Ele traz conhecimentos prévios e participa ativamente do próprio aprendizado. $\mathrm{O}$ ambiente de um jogo educativo, estimula o contato com letras, textos, gráficos e áudios, fazendo com que haja uma experimentação e desenvolvimento do raciocínio lógico, além de enfatizar que o erro é essencial para a reflexão e a auto avaliação. Com isso, os softwares educativos vêm para auxiliar o professor na aplicação de suas disciplinas, os quais podem ser como entretenimento, jogos e até em forma de disputa.

O avanço tecnológico acaba exigindo novos processos educacionais. Segundo LIBÂNEO (2011), essas exigências pedem um professor mais capaz de ajustar suas didáticas às novas realidades da sociedade, do conhecimento, do aluno e dos meios de 
comunicação. Mesmo assim, muitos softwares criados para o ensino não correspondem ao principal interesse que é ensinar e educar.

Portanto, este artigo aborda a utilização do software educacional direcionado à disciplina de Geografia do Brasil para alunos do ensino fundamental que tem por objetivo desenvolver a capacidade do aluno em identificar os estados brasileiros, suas bandeiras e suas respectivas cores, além de tornar o aprendizado mais interessante.

\section{Desenvolvimento}

O objetivo do jogo "GeoCor" é fazer com que o aluno visualize a bandeira de um estado e consiga identificar e escolher as cores correspondente, as quais estarão disponíveis dinamicamente. Além disso, é permitir um acréscimo à coordenação motora do aluno, proporcionando, também, o desenvolvimento de habilidades, conhecimentos $\mathrm{e}$ capacidades.

Foram utilizadas as seguintes etapas do processo de desenvolvimento: levantamento de requisitos, análise, projeto, implementação, teste e avaliação.

O levantamento de requisitos foi feito através de pesquisa de softwares educacionais aplicados à disciplina de Geografia do Brasil, onde, analisando alguns destes disponíveis, pode ser verificado que a maioria é feito com o objetivo de quiz e quando se trata de bandeiras geralmente corresponde às internacionais. Ou seja, nenhum dos encontrados correlaciona a identificação de cores às bandeiras dos estados brasileiros.

$\mathrm{Na}$ fase de análise, foi definido que o software será aplicado com os alunos do ensino fundamental a partir do $4^{\circ}$ ano, com o objetivo de auxiliar o processo ensinoaprendizagem e, além disso, trabalhar a coordenação motora e o reflexo da criança.

Abaixo, é descrito dois diagramas que propõem os detalhes da forma que o software será desenvolvido. O diagrama de atividade e de estado demonstra que o jogador ao iniciar o jogo avança entre as bandeiras informando suas respectivas cores e, dependendo de sua resposta tem um feedback informando se está correta ou não, variando assim sua pontuação e, por fim, finaliza o jogo.

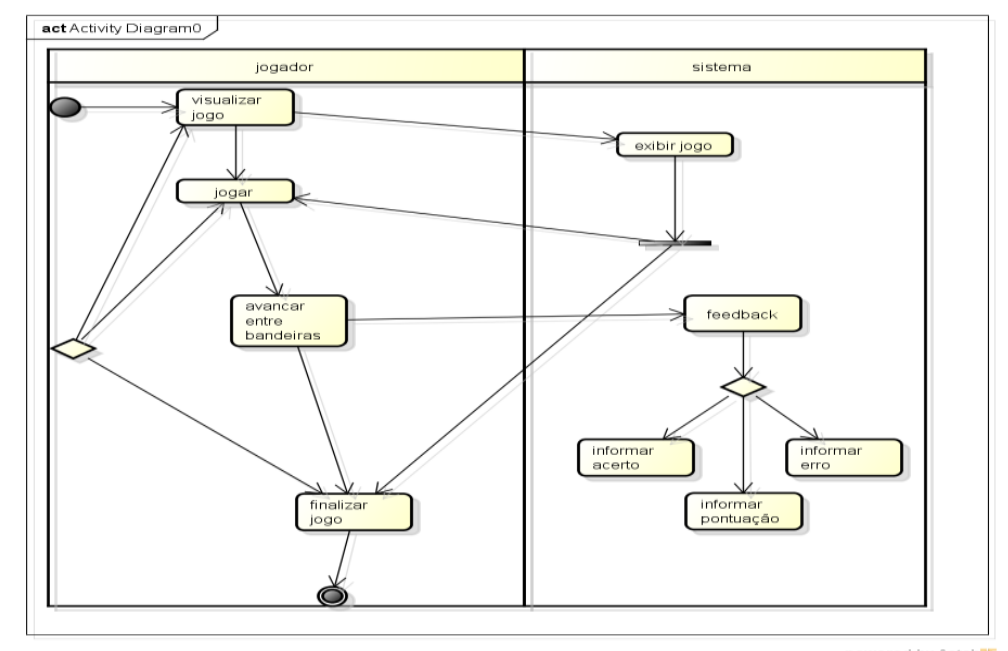


CBIE-LACLO 2015

Anais dos Workshops do IV Congresso Brasileiro de Informática na Educação (CBIE 2015)

Figura 1 - Diagrama de Atividades

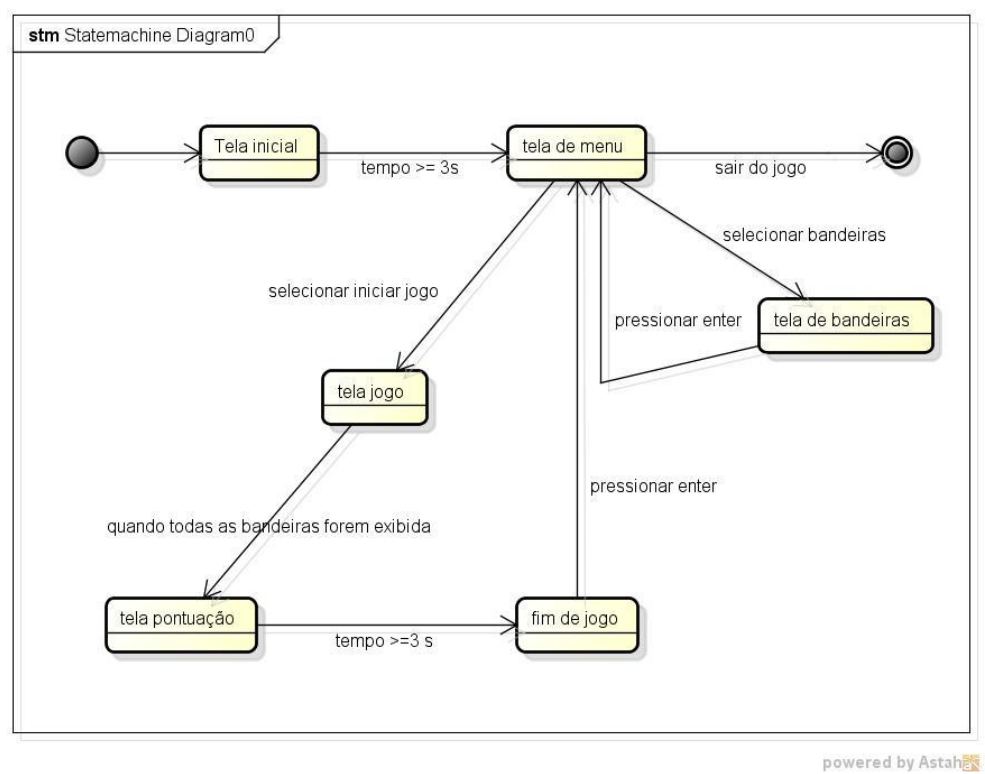

Figura 2 - Diagrama de Estado

A implementação do software educativo será feita com a ferramenta "Construct 2" o qual é um ambiente para desenvolvimento de jogos que agiliza e facilita a criação de games interplataforma. Utiliza as bibliotecas dos principais sistemas operacionais para criar jogos de maneira muito fácil. Sua preocupação será em criar uma história e desenvolver as imagens para dar vida e movimentos aos personagens e ao contexto do jogo.

A ferramenta possui uma programação intuitiva, bastando selecionar em seus componentes o comportamento predefinido dos personagens, cenários, trilha sonora e outros objetos da tela. Existe uma lista chamada "Event Sheet" onde é acrescentado o código de maneira simples. Existe um mini editor de imagens integrado, sem a necessidade de utilizar um plugin. No editor é possível cortar, girar, inverter a imagem, alterar a cor, criar uma animação com uma sequência de imagens.

Outra particularidade do programa que não pode ser isolada é o painel "Layers", onde é possível posicionar os objetos em camadas diferentes, semelhante ao Photoshop da Adobe. A partir dessas camadas é possível atribuir comportamentos diferentes para cada uma, organizando bastante o trabalho do desenvolvedor. O Construct 2 também possui uma janela para exportar o projeto, em formato para web, mobile, PC, formato Scirra Arcade (site onde ficam os jogos criados por usuários do site), Chrome Web Store, Kongregate, Windows 8 Metro app e outros.

Para a fase de teste, foi determinado que, primeiro o jogo educativo será apresentado e avaliado pelo professor da disciplina para que o mesmo possa adicioná-lo em sua metodologia de ensino. Após, os alunos terão acesso ao jogo através de computadores com acesso à internet e far-se-á uma aula interativa com atividades relacionando o conteúdo e o jogo. 
Por fim, será feita uma avaliação com a aplicação de um questionário, onde o professor da disciplina e os alunos responderão às perguntas objetivas para que sejam descritos os pontos positivos e negativos da aplicação do jogo em sala de aula, estimando o que pode ser melhorado no software com observações feitas pelos avaliadores.

\section{GeoCor}

O GeoCor tem como principal objetivo fazer com que o aluno visualize uma bandeira colorida e selecione os balões que correspondem às mesmas cores. Quando ele clica em um balão com a cor certa recebe 10 (dez) pontos. Quando deixa passar um balão com a cor diferente, ou seja, uma cor errada acrescenta um ponto. Quando um balão da cor certa passa e não é estourado perde um ponto. Conforme figura 3.

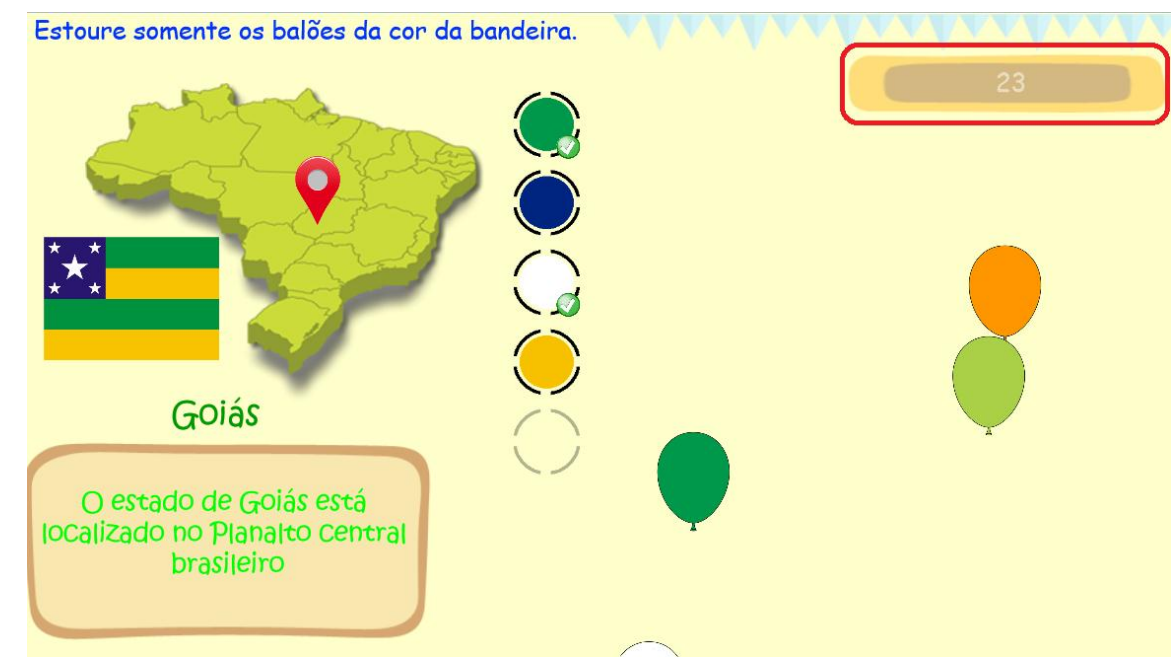

Figura 3 - Tela do Jogo: Pontuação

É também visualizado um mapa com a localização de cada estado. À medida que as bandeiras vão alterando, é indicado onde cada estado fica, além de um texto com uma característica do estado, como: capital, região, comidas típicas, etc. Essas informações são disponibilizadas de forma aleatória. Conforme figura 4. 


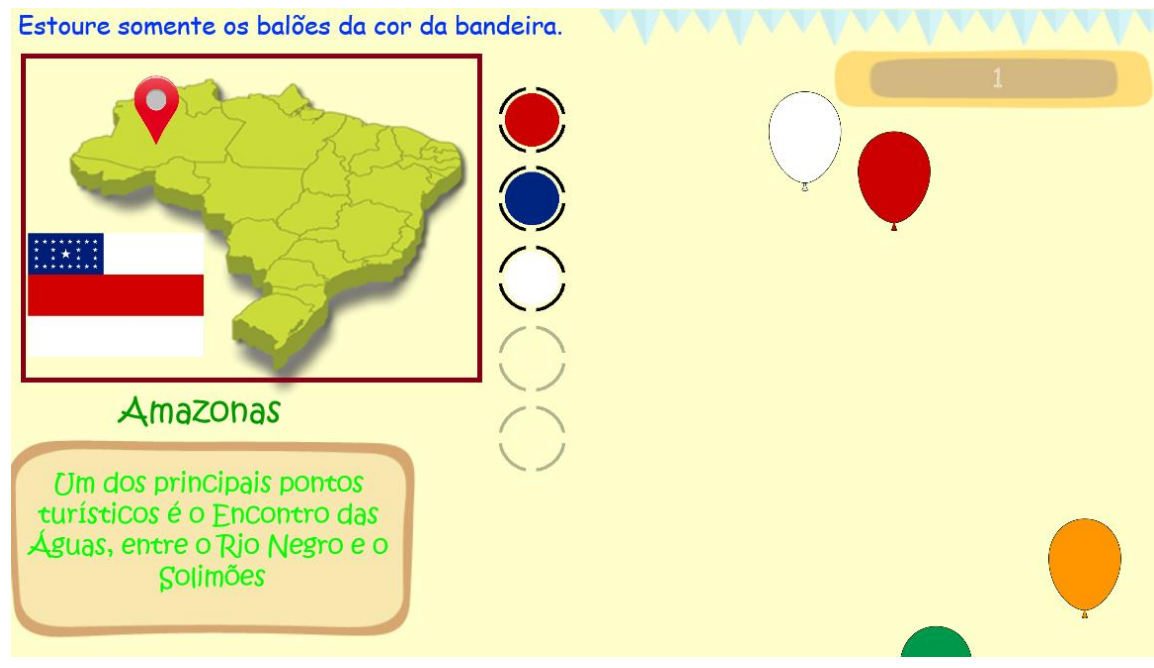

Figura 4 - Tela do Jogo: Mapa de Localização e Bandeira

Ao lado da bandeira e do mapa de localização é disponibilizado cinco itens que, conforme aparecem as bandeiras, a quantidade de suas respectivas cores são preenchidas. Segundo a figura 5 .

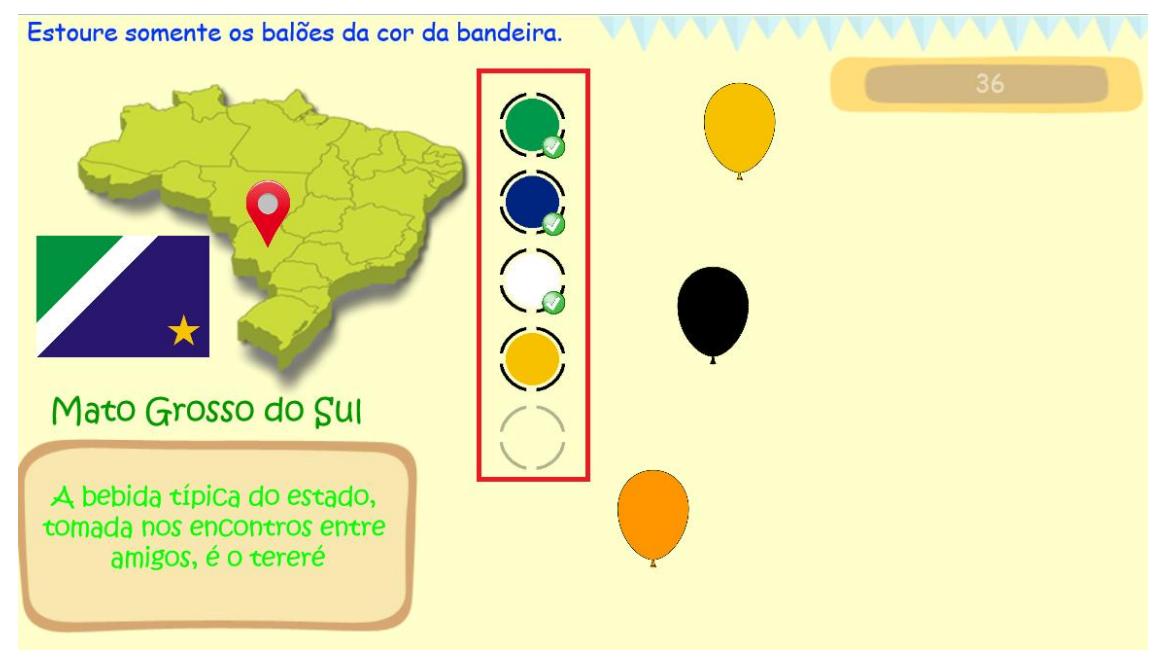

Figura 5 - Tela do Jogo: Cores

\section{Trabalhos Futuros}

A princípio o GeoCor terá apenas uma fase como demonstrado anteriormente. Porém, a continuidade do jogo se dará em:

FASE 2: O aluno visualizará o contorno da bandeira e o nome do estado e deverá escolher as cores que correspondem àquela bandeira. $\mathrm{O}$ aluno visualizará uma bandeira sem cor (ex: Bahia [azul, branco e vermelho]) com seu respectivo nome e várias cores em movimento, onde deverá clicar nas mesmas cores correspondentes à bandeira. Conforme figura 6 . 
CBIE-LACLO 2015

Anais dos Workshops do IV Congresso Brasileiro de Informática na Educação (CBIE 2015)

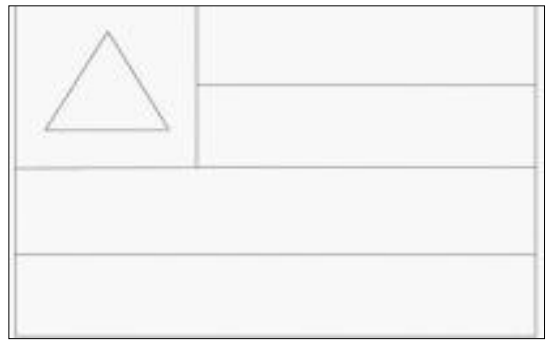

\section{BAHIA}

Figura 6 - Exemplo Fase 2: Bandeira

FASE 3: O aluno visualizará apenas o contorno da bandeira e deverá escolher as cores e as letras que correspondem àquela bandeira. Visualizará uma bandeira sem cor e sem nome e várias cores e letras em movimento, onde deverá clicar nas mesmas cores correspondentes à bandeira e nas mesmas letras que compõem o nome do estado.

\section{Conclusão}

A apresentação e a aplicação do software educativo possibilitou uma nova metodologia de ensino-aprendizagem aos alunos e professores do ensino fundamental. Baseou-se em conhecimentos na área de educação e computação. A coleta será feita através de observação, antes, durante e depois da aplicação do software, que também contará com uma breve entrevista com professor e com os alunos no primeiro dia de aplicação e no último, finalizando assim o processo de coleta.

Portanto, a submissão de um jogo na disciplina de geografia do Brasil veio a melhorar o desempenho da matéria em sala de aula visando uma adequação por parte do professor e dos alunos fazendo com que haja interação e aprendizagem.

\section{Referências Bibliográficas}

Almeida C. C. e Carvalho, L. P. "A formação de professores no curso de Licenciatura em Computação: um relato das práticas educacionais de iniciação a docência". XVIII WIE, Rio de Janeiro, 2012.

LIBANEO, J. C. "Adeus professor, adeus professora? : Novas exigências educacionais e profissão docente”. 13a ed. - São Paulo: Cortez, 2011. 